\title{
Megafauna in Salt Marshes
}

\author{
Leo C. Gaskins*, Avery B. Paxton ${ }^{\dagger}$ and Brian R. Silliman \\ Duke University Marine Lab, Beaufort, NC, United States
}

Megafauna shape ecosystems globally through trophic interactions, ecology of fear, and ecosystem engineering. Highly productive salt marshes at the interface of terrestrial and marine systems have the potential to support megafauna species, but a recent global meta-analysis of consumer-plant interactions in marshes found few studies investigated impacts of wild megafauna. We conducted a literature review to document the variety of megafauna in salt marshes and found that 34 species utilize salt marshes, including sharks, manatees, pinnipeds, crocodilians, sea otters, hippos, and large terrestrial animals, such as lions, bears and water buffalo. The use of salt marsh habitats by a variety of megafauna may have implications for both the conservation of these large consumers and for the resilience of coastal wetlands through stabilizing feedbacks on plant ecosystems. Future studies should quantify the occurrence and impacts of megafauna in salt marshes, and how their conservation can help restore these valuable ecosystems.

Keywords: megafauna, salt marsh, ecosystem resilience, coastal wetland, restoration

\section{INTRODUCTION}

Megafauna are animals $>45 \mathrm{~kg}$ (100 lbs) and shape ecosystem structure and function throughout the world (Martin and Klein, 1989). As consumers, megafauna often regulate ecosystems through feeding. Elephants, for instance, eat and remove trees and thereby promote competitively inferior grasses and grasslands ecosystems (Laws, 1970). Megafauna predators can also control their prey, and in doing so, can generate cascading effects by indirectly facilitating plant communities. For example, sea otters, by controlling densities of hold-fast grazing urchins, indirectly facilitate entire kelp communities (Estes and Palmisano, 1974). The indirect effects of predators can also manifest through the fear they impose on their prey. In Shark Bay, Australia, tiger sharks create cascading impacts through fear by driving dugongs and sea turtles to spend extended periods in unvegetated, shallow areas thereby generating top-down release on seagrasses in deeper waters (Burkholder et al., 2013). Large herbivores can also shape ecosystems through their non-feeding activities. Elephants can generate animal-driven nutrient fluxes by translocating nutrients through their feces, and models predict this activity constitutes an important nutrient supply for plants in savannah ecosystems (Wolf et al., 2013). Rhinos consume such a large volume of grass that they alter the fire regime in savanna ecosystems by significantly lowering the amount of fuel available to burn in large patches (Waldram et al., 2008). Historically, the vast influence of megaherbivores has also played an important role in shaping ecosystems, as their elimination by human hunters likely reshaped the ecosystem types and impacted small herbivore diversity (Owen-Smith, 1987). In systems where megafauna can occur in high densities, their impacts can be tremendous, and their loss or gain can change ecosystems and their resilience (Waldram et al., 2008; Hughes et al., 2013). For instance, the reemergence of sea otters on the west coast of the United States has revitalized seagrass habitats, as sea otter consumption of crabs facilitates sea slugs that protect seagrasses from algal overgrowth (Hughes et al., 2013). 
Megafauna are well-known to occur in a diversity of ecosystems, including terrestrial, freshwater, and marine. Despite their abundance in many ecosystems that occur juxtaposed to temperate coastal shorelines, including bays, nearshore oceanic shelves, maritime forests, and grasslands, megafauna are not mentioned in major text books about salt marshes nor included in the food-web models presented therein (Nybakken and Bertness, 2005; Bertness, 2007; Mitsch and Gosselink, 2007; Bertness et al., 2014). To examine whether this pattern is prevalent not only in textbooks but also in peer-reviewed literature, we analyzed a global dataset of 163 studies on marsh consumer effects ( $\mathrm{He}$ and Silliman, 2016) extracted from 178 studies of consumer-marsh plant interactions. This dataset revealed that $27 \%$ of studies (44) included a species of megafauna but that only 5 unique megafauna species were reported in total (Supplementary Figure 1A). Within the subset of studies reporting megafauna, $89 \%$ of studies (39) investigated 3 unique species of domesticated livestock (horses, cows, and sheep) while even fewer studies $(5,11 \%)$ focused on wild megafauna (Supplementary Figure 1B), and all were terrestrial megafauna species. These results suggest that both the number of megafauna species and the diversity of megafauna that utilize salt marsh habitats globally is low.

The notable and relatively recent expansions of American alligators and sea otters into salt marshes, along with a recent review study that found salt marshes are home to at least a few more megafauna (e.g., crocodiles, harbor seals) (Sievers et al., 2019), indicate that there are likely more megafauna species that utilize salt marshes than is represented in this global metaanalysis of top-down effects in salt marshes (He and Silliman, 2016). In southeastern United States salt marshes, for example, researchers found that in marine protected areas, densities of the American alligator (Alligator mississippiensis) were higher than in comparable freshwater systems (Nifong and Silliman, 2017; Silliman et al., 2018). Alligators not only fed on marine animals in salt marshes, but more than $50 \%$ of the gut contents were marine animals, such as blue crabs (Callinectes sapidus), shrimp, and string rays (Nifong and Silliman, 2013). In Elkhorn Slough in California, sea otters (Enhydra lutris) have re-colonized seagrasses and salt marshes and, like alligators, have thrived. After colonization of these new habitats, sea otters quickly started eating marsh invertebrates, with burrowing crabs now making up $19 \%$ of the diet of the 131 otters in the slough (Tinker et al., 2018). Taking into account the variation in body size and that otters consume $4.53-11.34 \mathrm{~kg}$ daily, this means the Elkhorn Slough otters consume between 112.75-282.25 kg daily of burrowing marsh crabs alone (Riedman and Estes, 1990; Tinker et al., 2018), which could have profound impacts on the salt marsh, as marsh plants and geomorphology can be highly regulated by crabs when their densities are high (Escapa et al., 2007). Given the outsized impact that megafauna can have on ecosystems, it is important to understand and quantify their impacts in marshes. However, whether a large number of megafauna species or a high diversity of megafauna occasionally or commonly occur in salt marshes has yet to be examined on a worldwide scale. To examine if textbooks and consumer effects studies truly capture the number or diversity of megafauna species in salt marshes, we conducted a literature review to search for additional megafauna species that commonly use salt marsh ecosystems as habitat.

\section{MATERIALS AND METHODS}

To investigate megafauna occurrence in salt marshes globally, we conducted a literature review to search for documented instances of megafauna in salt marshes. We conducted our search with the Web of Science on 18 December 2018 using the search query: TS $=\left(\right.$ shark $^{*}$ AND marsh $\left.{ }^{*}\right)$ OR TS $=\left(\right.$ crocodil $^{*}$ AND marsh $\left.*\right)$ OR TS $=\left(\right.$ mammal $^{*}$ AND marsh $\left.{ }^{*}\right)$ OR TS $=($ megafauna AND marsh) $\mathrm{OR}$ TS $=($ top predator AND marsh*) OR TS $=($ apex predator AND marsh*) OR TS = (top consumer AND marsh*). This search yielded 765 potentially relevant papers. For each of the papers, we imported the title and abstract to Colandr (Cheng et al., 2018) where we first reviewed titles and abstracts to screen articles for inclusion. Articles were retained for additional screening within Colandr if they included observations of any animal in salt marshes. We excluded articles that were not in English or were in freshwater but not saltwater marshes. After the initial screening, which yielded 214 papers, we conducted a second round of screening and retained articles where one or more species of megafauna is documented in salt marshes. We included animals that can reach over $45 \mathrm{~kg}$ (100 lbs) at some point in their life as megafauna, as most literature does not report the size or weight of animals in marshes. Though we recognize some records may have been of juveniles under $45 \mathrm{~kg}$, if a species has previously been documented to reach our $45 \mathrm{~kg}$ threshold, the species was included. For example, this drove our decision for sea otters, which can reach over $45 \mathrm{~kg}$ in Alaska, and hence were included (Estes et al., 2016). This definition of megafauna as $>45 \mathrm{~kg}$ (100 lbs) is commonly accepted in the scientific literature (Martin and Klein, 1989), and mass is the most commonly used way of defining megafauna (Moleón et al., 2020). We included wild, domesticated, and semidomesticated animals. Following the second round of screening, which produced 31 papers that were directly from the literature search or referenced in these texts, we conducted a final review to extract the species name and salt marsh location where megafauna have been documented. We then conducted a final verification that the animals were classified as megafauna and that the animals were documented in salt marshes, rather than solely near salt marshes. With this final verification, we reduced the number of applicable papers to 23. Though our search captured many megafauna species in salt marshes, there are likely more contained in peer-reviewed literature that were not identified in our literature search, or gray literature not searched. In multiple cases, salt marshes and other ecosystems were mentioned in papers. In these cases, we included the megafauna only if the species was clearly documented as occurring in salt marshes. For example, one paper referencing green turtles (Chelonia mydas) primarily focuses on mangroves, but explicitly states that Spartina alterniflora, a salt marsh grass, was important to the diet and ecology of green sea turtles, so this megafauna species was included (Nagaoka et al., 2012). 
We also incorporated visual observations of additional megafauna that were not discovered in the literature search but have been observed in salt marshes by ourselves or a subset of our colleagues. For example, a colleague provided photographs documenting megafauna in South African salt marshes. While our approach likely is not exhaustive, our goal was not to find every instance of megafauna occurrence in salt marshes, but to test whether the diversity of megafauna that utilize salt marshes is greater than suggested by past studies. When compiling megafauna species that use salt marshes, we did not require density data, as these data were rarely reported. Instead, we opted for presence data. When density data were available, however, we recorded them, as well (Supplementary Table 1). Future studies should conduct a more systematic survey of marsh scientists for a more comprehensive view into megafauna use of salt marshes.

\section{DISCUSSION}

In total, the literature review yielded 34 megafauna species that utilize salt marshes (Figures 1A-C, Supplementary Figure 2). This richness of megafauna represents a great expansion beyond the diversity of megafauna represented in the global metaanalysis of consumer-plant interactions in salt marshes (He and Silliman, 2016), and demonstrates that there are a large variety of megafauna taxa that utilize salt marshes throughout the globe (Supplementary Table 1). While most studies reported megafauna presence, several studies from the literature review reported megafauna densities, which were comparable to or higher than those in habitats in which they are established (Supplementary Table 1). For example, density of black bears in salt marshes $\left(0.23\right.$ bears $\left./ \mathrm{km}^{2}\right)$ was similar to black bear density in Alaskan forests $\left(0.26\right.$ bears $\left./ \mathrm{km}^{2}\right)$. Sea otter, harbor seal, wild horse, and alligator densities had a higher relative abundance in salt marshes than in other established habitats (Figure 2). We predict that salt marshes, because of their high primary and secondary productivity, could be generally attractive ecosystems for megafauna in search of food and/or nursery grounds and that the diversity of megafauna using marshes will continue to increase as megafauna recover from overexploitation, as occurred with sea otters and alligators (Silliman et al., 2018). Additionally, the large difference between the diversity of animals within consumer effects studies and those who use salt marshes globally indicates that, while there are several megafauna species, such as alligators and hogs, whose impacts have been documented, there are likely animals impacting salt marshes whose effects have not been quantified.

Feral and introduced megafauna have been documented to impact saltmarsh structure and function. For example, feral hog activity not only leads to highly trampled areas and loss of vegetation, but also changes in soil organic carbon, marsh elevation, soil anoxia, higher concentrations of ammoniumnitrogen in porewater, and changes in carbon cycling (Persico et al., 2017; Sharp and Angelini, 2019). Studies on feral horses show that they can also greatly alter salt marsh communities, increasing bird diversity and crab densities, but lowering the amount of vegetation biomass and the fish species richness in grazed marshes (Turner, 1987; Levin et al., 2002). Additionally, overpopulated feral horses can graze the marsh so extensively it cannot recover (Turner, 1988). These strong indirect impacts on salt marsh structure, resilience, and function are noteworthy and important to understand and preserve important salt marsh functions. Future work should focus on managing and mitigating the impacts of introduced and feral animals. This would not only aid in the recovery of native wild megafauna in these spaces but also protect the marsh ecosystems themselves. While impacts of feral and introduced megafauna on marshes are relatively well understood, the impacts of recovered, native megafauna species are less well understood.

The presence of a diversity of megafauna in salt marshes, including recovered native megafauna, has a range of potential implications for salt marsh ecosystem structure and function. First, megafauna may exert positive or potentially negative influences on foundational salt marsh species, such as grasses. Evidence that consumptive and non-consumptive impacts of alligators can trigger trophic cascades that indirectly promote snail and mussel populations supports this hypothesis (Nifong and Silliman, 2013). Second, direct vegetation consumption by cattle and horses in Europe provides important insight into the impact of grazing on salt marshes (Menard et al., 2002; Nolte et al., 2014). Because of differences in nutritional requirements and plant species preferences, cattle and horses contribute differently to structural diversity and ecosystem management, and this information can be used to minimize negative impacts on foundational marsh plant species (Menard et al., 2002). Third, megafauna may stabilize feedbacks of predators on plant ecosystems, thereby providing increased coastal ecosystem resilience. For example, wetland predators, such as blue crabs and sea otters, induce trophic cascades through mesopredator and grazer consumption that promote plant populations (Silliman and Bertness, 2002; Hughes et al., 2013). These more robust foundational plant populations could improve ecosystem resilience by stabilizing sediment with their roots and lowering erosion rates, improving coastal protection by wetlands (Silliman et al., 2019). Fourth, megafauna facilitation of foundational plant species (Hughes et al., 2013) could improve restoration approaches, leading to cost and effort savings, as facilitation of plant foundational species could proceed on its own with the proper restoration design. For example, through a trophic cascade, sea otters restored hectares of seagrass, the foundational plant species in the system, by consuming crabs that eat sea slugs which clean algae off the seagrass. The end result was that seagrasses were restored in the estuary without human intervention (Hughes et al., 2013). Fifth, large animals like hippos, water buffalo, and manatees could severely suppress standing plant biomass and/or create ponds within marshes, similarly to the way invasive feral hogs do now (Frederick, 1998; Arrington et al., 1999). Because these five potential influences of megafauna on salt marsh ecosystems remain largely theoretical and hypothetical, future studies should focus on quantifying effects of megafauna on salt marsh structure and function and whether megafauna presence can be harnessed for conservation and restoration of these important coastal ecosystems. Additionally, we defined megafauna on the 


\section{A}

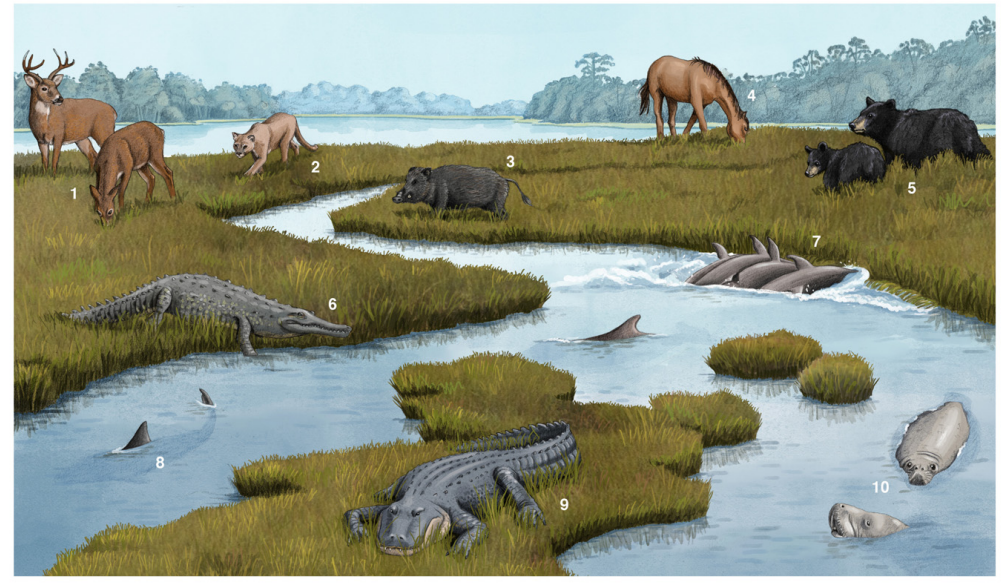

B

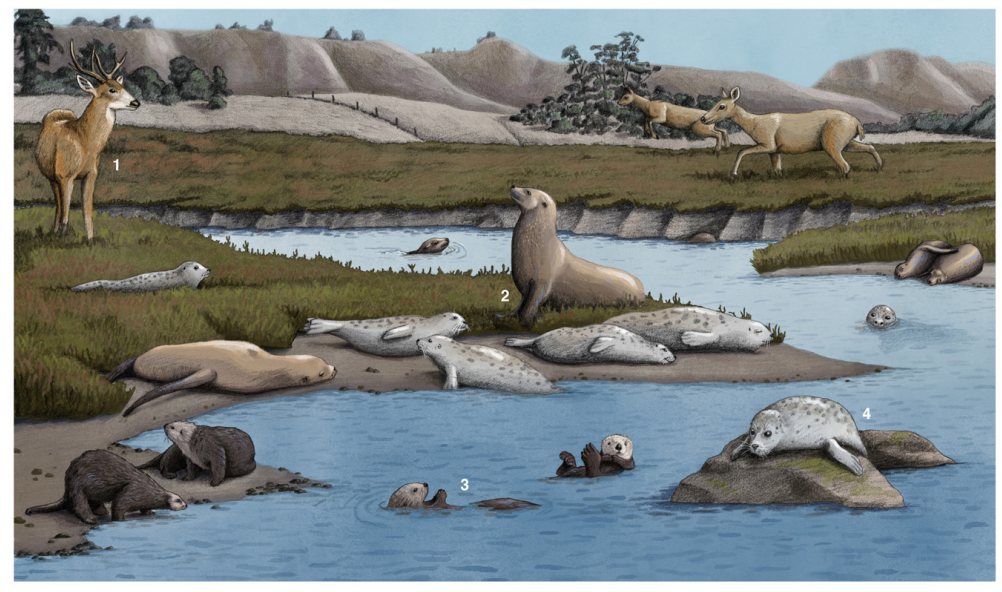

C

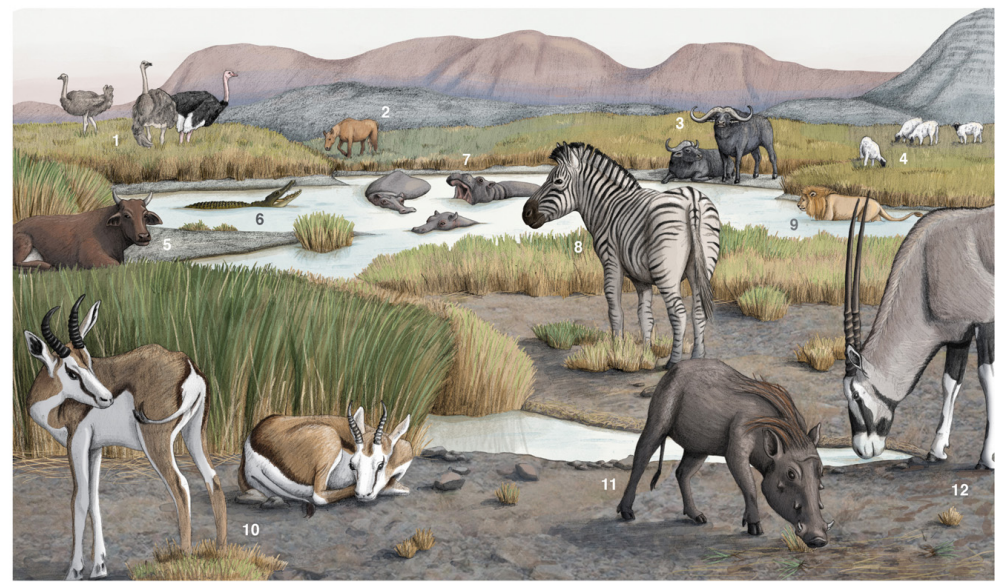

FIGURE 1 | (A) Megafauna in southeastern salt marshes including (1) white-tailed deer (Odocoileus virginianus), (2) Florida panther (Puma concolor coryi), (3) wild boar (Sus scrofa), (4) wild horse (Equus ferus), (5) black bear (Ursus americanus), (6) American crocodile (Crocodylus acutus), (7) bottlenose dolphin (Tursiops truncatus), (8) bull shark (Carcharhinus leucas), (9) American alligator (Alligator mississippiensis), and (10) west Indian manatee (Trichechus manatus). These are artistic illustrations and do not represent actual spacing among or abundance of megafauna. Artwork by Alex Boersma. (B) Megafauna in Elkhorn Slough, California salt marshes, including (1) mule deer (Odocoileus hemionus), (2) sea lions (Zalophus californianus), (3) sea otters (Enhydra lutris), and (4) harbor seals (Phoca vitulina). These are artistic illustrations and do not represent actual spacing among or abundance of megafauna. Artwork by Alex Boersma. (C) Megafauna in South African salt marshes, including (1) ostrich (Struthio camelus), (2) domesticated horse (Equus ferus caballus), (3) African buffalo (Syncerus caffer), (4) sheep (Ovis aries), (5) cattle (Bos taurus), (6) Nile crocodile (Crocodylus niloticus), (7) hippopotamus (Hippopotamus amphibius), (8) common zebra (Equus quagga burchellii), (9) lion (Panthera leo), (10) springbok (Antidorcas marsupialis), (11) common warthog (Phacochoerus africanus), (12) gemsbok (Oryx gazella). These are artistic illustrations and do not represent actual spacing among or abundance of megafauna. Artwork by Alex Boersma. 


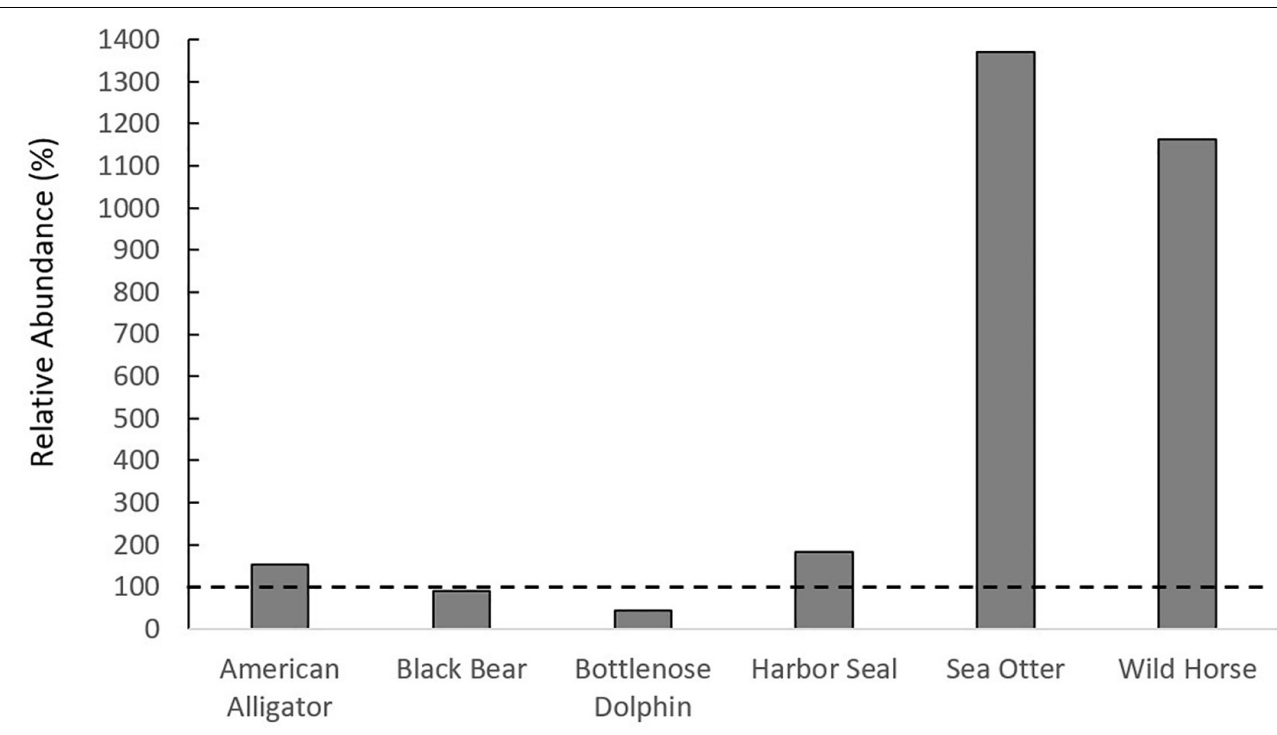

FIGURE 2 | Relative abundance of megafauna in salt marshes compared to other habitats in which they are found. If above the dashed horizontal line, the species of megafauna is more abundant in salt marshes than other habitats.

basis of mass (e.g., $45 \mathrm{~kg}$ ) but recommend that as future studies gain more insight into the roles of megafauna in salt marshes that salt marsh megafauna be classified functionally, as proposed by Moleón et al. (2020).

The use of salt marshes by a variety of megafauna suggests that marshes could provide important ecological functions for these animals - including providing additional habitat for feeding and raising young, and refugia from human impacts. For example, sea otters, an endangered species, likely use salt marshes as nursery grounds for several reasons, including that the marshes are relatively free from otter predators, that "hauling out" on salt marshes can be metabolically favorable for otters because body heat is lost more slowly in air than in water, and Elkhorn Slough marshes are low relief and otters can easily haul out onto them (Estes et al., 1998; Eby et al., 2017; Tinker et al., 2018). The degree of megafauna impacts on marshes likely depends upon species life stage. For example, if megafauna use salt marshes as juveniles, then their impacts may be reduced relative to those of larger, adult megafauna, yet additional research is necessary to test this. In terms of protection from human impacts, salt marshes likely serve as a refuge for the American crocodile and West Indian manatee, which are both listed as vulnerable by the IUCN Red List (Deutsch et al., 2008; Ponce-Campos et al., 2012; Sievers et al., 2019). The recognition that megafauna can be supported in marsh systems adds to and strengthens the list of known ecological services that salt marshes provide, such as increased coastal protection and erosion control through trophic cascades that positively impact foundational plant species, and water purification and carbon sequestration from marshes under less stress from overgrazing (Barbier et al., 2011; Silliman et al., 2019). Given the importance of salt marshes to species of megafauna, future marsh restoration and management plans should consider the ecological functions that marshes can provide for megafauna.

\section{DATA AVAILABILITY STATEMENT}

Publicly available datasets were analyzed in this study. This data can be found here: https://esajournals.onlinelibrary.wiley.com/ doi/10.1002/ecm.1221.

\section{AUTHOR CONTRIBUTIONS}

LG, AP, and BS contributed to conception and design of the study. AP and LG performed the literature review and analysis. All authors contributed to manuscript initial drafts, revision, read, and approved the submitted version.

\section{FUNDING}

LG was supported by the NSF Graduate Research Fellowship, Grant no. DGE-1644868. This work was supported by grants from the Oak Foundation and the Lenfest Ocean Program to BS.

\section{ACKNOWLEDGMENTS}

We thank J. Morton for his feedback on our manuscript and his observations, D. Onorato for his observation, and J. Nifong and R. Eby for sharing their photographs of alligators and sea otters in salt marshes, respectively. A special thank you to J. B. Adams for sharing her megafauna observations.

\section{SUPPLEMENTARY MATERIAL}

The Supplementary Material for this article can be found online at: https://www.frontiersin.org/articles/10.3389/fmars.2020. 561476/full\#supplementary-material 


\section{REFERENCES}

Arrington, D. A., Toth, L. A., and Koebel, J. W. (1999). Effects of rooting by feral hogsSus scrofa L. on the structure of a floodplain vegetation assemblage. Wetlands 19, 535-544. doi: 10.1007/bf03161691

Barbier, E. B., Hacker, S. D., Kennedy, C., Koch, E. W., Stier, A. C., and Silliman, B. R. (2011). The value of estuarine and coastal ecosystem services. Ecol. Monogr. 81, 169-193.

Bertness, M. D. (2007). Atlantic Shorelines: Natural History and Ecology. Princeton, NJ: Princeton University Press.

Bertness, M. D., Bruno, J. F., Silliman, B. R., and Stachowicz, J. J. (2014). Marine Community Ecology and Conservation. Sunderland, MA: Sinauer Associates.

Burkholder, D. A., Heithaus, M. R., Fourqurean, J. W., Wirsing, A., and Dill, L. M. (2013). Patterns of top-down control in a seagrass ecosystem: could a roving apex predator induce a behaviour-mediated trophic cascade? J. Anim. Ecol. 82, 1192-1202. doi: 10.1111/1365-2656.12097

Cheng, S., Augustin, C., Bethel, A., Gill, D., Anzaroot, S., Brun, J., et al. (2018). Using machine learning to advance synthesis and use of conservation and environmental evidence. Conserv. Biol. 32, 762-764. doi: 10.1111/cobi.13117

Deutsch, C., Self-Sullivan, C., and Mignucci-Giannoni, A. (2008). Trichechus manatus. The IUCN Red List of Threatened Species 2008:e.T22103A9356917.

Eby, R., Scoles, R., Hughes, B. B., and Wasson, K. (2017). Serendipity in a salt marsh: detecting frequent sea otter haul outs in a marsh ecosystem. Ecology 98, 2975-2977. doi: 10.1002/ecy.1965

Escapa, M., Minkoff, D. R., Perillo, G. M., and Iribarne, O. (2007). Direct and indirect effects of burrowing crab Chasmagnathus granulatus activities on erosion of southwest Atlantic Sarcocornia-dominated marshes. Limnol. Oceanogr. 52, 2340-2349. doi: 10.4319/lo.2007.52.6.2340

Estes, J. A., Heithaus, M., McCauley, D. J., Rasher, D. B., and Worm, B. (2016). Megafaunal impacts on structure and function of ocean ecosystems. Annu. Rev. Environ. Resour. 41, 83-116. doi: 10.1146/annurev-environ-110615-085622

Estes, J. A., and Palmisano, J. F. (1974). Sea otters: their role in structuring nearshore communities. Science 185, 1058-1060. doi: 10.1126/science.185. 4156.1058

Estes, J. A., Tinker, M. T., Williams, T. M., and Doak, D. F. (1998). Killer whale predation on sea otters linking oceanic and nearshore ecosystems. Science 282, 473-476. doi: 10.1126/science.282.5388.473

Frederick, J. M. (1998). “Overview of wild pig damage in California," in Proceedings of the Vertebrate Pest Conference, California.

He, Q., and Silliman, B. (2016). Consumer control as a common driver of coastal vegetation worldwide. Ecol. Monogr. 86, 278-294. doi: 10.1002/ecm.1221

Hughes, B. B., Eby, R., Van Dyke, E., Tinker, M. T., Marks, C. I., Johnson, K. S., et al. (2013). Recovery of a top predator mediates negative eutrophic effects on seagrass. Proc. Natl. Acad. Sci. U.S.A. 110, 15313-15318. doi: 10.1073/pnas. 1302805110

Laws, R. M. (1970). Elephants as agents of habitat and landscape change in East Africa. Oikos 21, 1-15. doi: 10.2307/3543832

Levin, P. S., Ellis, J., Petrik, R., and Hay, M. E. (2002). Indirect effects of feral horses on estuarine communities. Conserv. Biol. 16, 1364-1371. doi: 10.1046/j.15231739.2002.01167.x

Martin, P. S., and Klein, R. G. (1989). Quaternary Extinctions: A Prehistoric Revolution. Tucson, AZ: University of Arizona Press.

Menard, C., Duncan, P., Fleurance, G., Georges, J. Y., and Lila, M. (2002). Comparative foraging and nutrition of horses and cattle in European wetlands. J. Appl. Ecol. 39, 120-133. doi: 10.1046/j.1365-2664.2002.00693.x

Mitsch, W. J., and Gosselink, J. G. (2007). Wetlands. Hoboken, NJ: John Wiley \& Sons.

Moleón, M., Sánchez-Zapata, J. A., Donázar, J. A., Revilla, E., Martín-López, B., Gutiérrez-Cánovas, C., et al. (2020). Rethinking megafauna. Proc. R. Soc. B 287:20192643.

Nagaoka, S. M., Martins, A. S., Dos Santos, R. G., Tognella, M. M. P., de Oliveira Filho, E. C., and Seminoff, J. A. (2012). Diet of juvenile green turtles (Chelonia mydas) associating with artisanal fishing traps in a subtropical estuary in Brazil. Mar. Biol. 159, 573-581. doi: 10.1007/s00227-011-1836-y
Nifong, J. C., and Silliman, B. (2017). Abiotic factors influence the dynamics of marine habitat use by a highly mobile "freshwater" top predator. Hydrobiologia 802, 155-174. doi: 10.1007/s10750-017-3255-7

Nifong, J. C., and Silliman, B. R. (2013). Impacts of a large-bodied, apex predator (Alligator mississippiensis Daudin 1801) on salt marsh food webs. J. Exp. Mar. Biol. Ecol. 440, 185-191. doi: 10.1016/j.jembe.2013.01.002

Nolte, S., Esselink, P., Smit, C., and Bakker, J. P. (2014). Herbivore species and density affect vegetation-structure patchiness in salt marshes. Agric. Ecosyst. Environ. 185, 41-47. doi: 10.1016/j.agee.2013.12.010

Nybakken, J., and Bertness, M. (2005). Marine Biology: An Ecological Approach, 6th Edn. San Francisco, CA: Pearson Education.

Owen-Smith, N. (1987). Pleistocene extinctions: the pivotal role of megaherbivores. Paleobiology 13, 351-362. doi: 10.1017/s0094837300008927

Persico, E. P., Sharp, S. J., and Angelini, C. (2017). Feral hog disturbance alters carbon dynamics in southeastern US salt marshes. Mar. Ecol. Prog. Ser. 580, 57-68. doi: 10.3354/meps12282

Ponce-Campos, P., Thorbjarnarson, J., and Velasco, A. (2012). Crocodylus acutus. The IUCN Red List of Threatened Species 2012:E.T5659A3043244.

Riedman, M., and Estes, J. A. (1990). The sea otter (Enhydra lutris): behavior, ecology, and natural history. Biol. Rep. 90, 1-126.

Sharp, S. J., and Angelini, C. (2019). The role of landscape composition and disturbance type in mediating salt marsh resilience to feral hog invasion. Biol. Invasions 21, 2857-2869. doi: 10.1007/s10530-019-02018-5

Sievers, M., Brown, C. J., Tulloch, V. J., Pearson, R. M., Haig, J. A., Turschwell, M. P., et al. (2019). The role of vegetated coastal wetlands for marine megafauna conservation. Trends Ecol. Evol. 34, 807-817. doi: 10.1016/j.tree.2019.04.004

Silliman, B. R., and Bertness, M. D. (2002). A trophic cascade regulates salt marsh primary production. Proc. Natl. Acad. Sci. U.S.A. 99, 10500-10505. doi: 10. 1073/pnas.162366599

Silliman, B. R., He, Q., Angelini, C., Smith, C. S., Kirwan, M. L., Daleo, P., et al. (2019). Field experiments and meta-analysis reveal wetland vegetation as a crucial element in the coastal protection paradigm. Curr. Biol. 29, 18001806.e3.

Silliman, B. R., Hughes, B. B., Gaskins, L. C., He, Q., Tinker, M. T., Read, A., et al. (2018). Are the ghosts of nature's past haunting ecology today? Curr. Biol. 28, R532-R537.

Tinker, M. T., Espinosa, S. M., Staedler, M. M., Tomoleoni, J. A., Fujii, J., Eby, R., et al. (2018). "The population status and ecology of sea otters in elkhorn slough, California," in Final Report for California Coastal Conservancy and U.S. Fish and Wildlife Service Oakland, CA: California Coastal Conservancy.

Turner, M. G. (1987). Effects of grazing by feral horses, clipping, trampling, and burning on a Georgia salt marsh. Estuaries 10, 54-60. doi: 10.2307/1352025

Turner, M. G. (1988). Simulation and management implications of feral horse grazing on Cumberland Island, Georgia. Rangel. Ecol. Manag. 41, 441-447. doi: $10.2307 / 3899586$

Waldram, M. S., Bond, W. J., and Stock, W. D. (2008). Ecological engineering by a mega-grazer: white rhino impacts on a South African savanna. Ecosystems 11, 101-112. doi: 10.1007/s10021-007-9109-9

Wolf, A., Doughty, C. E., and Malhi, Y. (2013). Lateral diffusion of nutrients by mammalian herbivores in terrestrial ecosystems. PLoS One 8:e71352. doi: 10.1371/journal.pone.0071352

Conflict of Interest: AP was employed by the company CSS Inc.

The remaining authors declare that the research was conducted in the absence of any commercial or financial relationships that could be construed as a potential conflict of interest.

Copyright (c) 2020 Gaskins, Paxton and Silliman. This is an open-access article distributed under the terms of the Creative Commons Attribution License (CC BY). The use, distribution or reproduction in other forums is permitted, provided the original author(s) and the copyright owner(s) are credited and that the original publication in this journal is cited, in accordance with accepted academic practice. No use, distribution or reproduction is permitted which does not comply with these terms. 